\title{
KOLONISATIE IN SURINAME
}

DOOR

L. DE WAAL

Een Kolonisatie-Schema voor eene bepaalde landstreek of gebied wordt beinvloed door en dient dus rekening te houden met een aantal factoren, waarvan het meerendeel als onveranderlijk aanvaard dient te worden, andere aan onze plannen dienstbaar gemaakt kunnen worden, enkele van onze keuze of wil afhankelijk zijn.

Onder de eerstbedoelden behooren: de uitgestrektheid en samenstelling der beschikbare gronden, hun topografische gesteldheid en de heerschende meteorologische omstandigheden, resp.: de hoogteligging boven den zeespiegel, alle factoren die van invloed zijn op de keuze der te verbouwen producten.

\section{Invloed der witgestrektheid}

Immers, bij aanwezigheid van groote, aaneengesloten complexen van overigens aan de te stellen eischen voldoende gronden, zal de keuze kunnen vallen op producten van den grooten landbouw, die in een centrale fabriek of inrichting verwerkt moeten worden, waarbij de transport kosten een belangrijke rol spelen.

Zijn die complexen van kleinere uitgestrektheid en overigens goede hoedanigheid, zoo kunnen deze niet in aanmerking komen voor exploitatie door den grooten landbouw, (afstand $\mathrm{v} / \mathrm{h}$ verwerkingscentrum) doch deze zullen voor afzonderlijke hoeven bestemd dienen te worden, al dan niet in samenwerking met degrootelandbouwbedrijven, afhankelijk van hunne ligging ten opzichte dier ondernemingen en der op de hoeven te telen producten. 


\section{De hoedanigheid der gronden}

Hoewel, zooals gezegd, aan de hoedanigheid der gronden, wat hunne samenstelling betreft, door den mensch niets veranderd kan worden, bestaat er toch een groote verscheidenheid daarvan en kan er dus in zooverre sprake zijn van keuze, dat men aan bepaalde complexen van zekere grondsoorten, die voor verschillende cultuurgewassen gewenscht of geschikt zijn, ook verschillende bestemmingen kan geven, in verband met andere omstandigheden of te stellen eischen.

\section{Topografische gesteldheid}

Hierbij speelt de behoefte aan vocht eene rol, zoodat op heuvels of geaccidenteerd terrein als regel geene producten in aanmerking komen, die een groote behoefte aan vocht hebben, b.v. rijst. Bij hellingen tot 1: 5 kan door terrassen-aanleg de rijstcultuur nog mogelijk gemaakt worden; bij zwaardere hellingen tot $1: 2$ zijn koffie, mais, thee enz. nog zeer goed te verbouwen, terwijlvoor de veeteelt zelfs steilere hellingen nog te benutten zijn.

\section{Meteorologische omstandigheden resp.: hoogte-ligging}

Als gevolg der lagere temperatuur en grooteren neerslag der op grootere hoogte gelegen terreinen, kunnen deze niet dienen voor producten, die voor hunne rijping een hoogere temperatuur en droogte noodig hebben b.v. suikerriet, doch voor die welke of geen hoogere temperatuur daarvoor behoeven (b.v. koffie) òf wier product niet uit de vrucht, doch uit het te oogsten blad bestaat b.v. thee of vezelplanten.

Ook kunnen deze met voordeel voor de veeteelt benut worden.

Onder de aan onzen wil dienstbaar te maken factoren kunnen gerekend worden de drooglegging of draineering en bevloeiing, al naar gelang de overigens aan te stellen ei- 
schen voldoende gronden te groote of te geringe vochtigheid hebben om het gekozen product met succes te kunnen verbouwen; alsmede de structuurveranderingen door aanwending van physische middelen en het beïnvloeden der samenstelling door het planten en onderploegen van bepaalde gewassen als b.v. leguminosen, die door de vastlegging der atmosferische stikst of deze in voor de planten opneembaren vorm in den bodem brengen; en ten slotte door directe bemesting met chemische (kunst) meststoffen, een middel dat in den regel slechts bij zeer intensief gedreven cultuur loonend is en langjarige proefneming vereischt.

De van onze keuze geheel afhankelijke factor is ten laatste de persoonlijke factor, de kolonist, die van overwegenden invloed is op het te behalen succes bij de kolonisatie en waarvan de keuze beslissend daarvoor kan worden genoemd.

Waar, zooals uit het voorgaande duidelijk is, slechts door middel van twee factoren invloed op het welslagen der kolonisatie kan worden uitgeoefend, n.l. door de keuze der gronden (in verband met het te planten product) en den persoonlijken factor, moge deze laatste allereerst aan eene nadere beschouwing onderworpen worden en eenige opmerkingen eene plaats vinden, mede in verband met eenige in het Hoofdstuk ,Immigratie en Kolonisatie" van het Rekest van den Ondernemersraad voor Suriname geuite denkbeelden.

\section{Stelsel van Kolonisatie}

Bedoeld Rekest zegt o.m. op blz. 3, 4e alinea: „maar „wèl acht onze Raad de stelling niet aanvechtbaar, dat „voor Suriname de tot dusver gevolgde weg, waarbij de „plantages gebruikt worden om de aangevoerde Javanen „op te voeden tot zelfstandige kolonisten, ook in de toe„komst moet worden beschouwd als $d e$ weg, welke het „zekerst en met het minste risico voor het Gouvernement 
,tot het doel leidt; dat dus de belegging van nieuw kapi"taal in Surinaamsche ondernemingen in het algemeen en ",in den grooten landbouw in het bijzonder als het aange"wezen middel moet worden beschouwd, om het doel: "sneller vermeerdering van bevolking te bereiken".

Naar mijne bescheiden meening worden „doel" en „middel" hier verwisseld; de ondernemingen zijn het doel, waartoe men geraken wil en één der middelen om het bestaan daarvan mogelijk te maken, is een voldoend aantal werkkrachten.

Wat nu die „Vermeerdering van bevolking” betreft, (Speciaal is hier sprake van Javanen) zij het volgende opgemerkt: De ondervinding leert dat de Javaansche bevolking zich zeer snel vermeerdert en moeten niet meer Javanen worden aangevoerd, dan in 't vigeerende stelsel verwacht kunnen worden direct of binnen afzienbaren tijd emplooi te zullen vinden. Wat er meer wordt aangevoerd wordt armlastig voor den Staat en niet voor korten tijd, doch tot tijd en wijle er meer vraag ontstaat, hetgeen afhankelijk is van de uitbreiding resp.: de oprichting van nieuwe ondernemingen. Daar hieraan echter aanvrage of koop van gronden en kapitaal-verstrekking vooraf dienen te gaan zijn deze plannen tijdig genoeg bekend om daarmede rekening te kunnen houden in zake de werkvolk-questie. Tegen het op Java voorbereiden en gereedhouden van eenige contingenten, om op eerste aanvrage te vertrekken behoeft intusschen geen bezwaar te bestaan.

Een ander punt in de bovenaangehaalde passage betreft de opleiding op de plantages van zelfstandige kolonisten uit de Javaansche Immigranten. Deze wordt genoemd de weg, die het zekerst en met de minste risico voor het Gouvernement tot het doel leidt.

Er moge in dit denkbeeld een ideeële kern zijn, dat het de bovenvermelde uitkomst zoude hebben is oppractische gronden niet aan te nemen.

$1^{\circ}$. Wordt met ,zelfstandige kolonisten” bedoeld „op den duur ,welvarende" kolonisten, dan is twijfel gerechtvaardigd aan het welslagen dezer poging, gezien de tot 
heden bereikte resultaten van vestiging van Javanen, waar van een "tot welvaart komen" geen sprake is geweest.

Hiertegen zou eventueel kunnen worden aangevoerd dat deze menschen niet de goede landbouwopleiding hebben genoten, welke nu van de plantages wordt verwacht. Welke „opleiding” stelt men zich echter voor, dat de Javanen op de groote ondernemingen zullen ontvangen? In de eerste plaats is de plantage noch kan zij zijn de aangewezen plaats tot vorming van kolonisten. Wie bekend is met den gang van zaken op eene onderneming, hetzij dan suiker-, koffie- of andere onderneming is ook bekend met het feit dat geen der daarop werkende Europeanen van hoog tot laag ook slechts den tijd zou kunnen vinden om zich met die vorming bezig te houden, afgescheiden nog van de vraag of zij daartoe de noodige geschiktheid zouden bezitten.

Zoude men dit denkbeeld willen doorzetten, dan zoude dit op den weg liggen van primaire landbouwscholen of door het oprichten van demonstratie-velden, zooals dit in Argentinië en Brazilië plaats heeft. Voor zoover het de op leiding van Javanen betreft, blijft de kans van slagen van zulk een systeem evenwel hoogst twijfelachtig, om het minste ervan te zeggen.

\section{Risico v/h Gouvernement}

$2^{\circ}$. Blijkt uit het bovenstaande reeds, dat bij verwezenlijking van het genoemde systeem "paupers" in stede van welvarende Kolonisten zouden worden gekweekt, zoo volgt daaruit onmiddellijk dat de risico voor het Gouvernement juist een maximale zoude zijn wegens het nietslagen der door de Regeering ondernomen en geleide kolonisatie en de gevolgen van dien.

Er is echter meer. Op blz. 15 bespreekt de Ondernemersraad voor Suriname hoe hij zich de inrichting en werking van een Javaansche Immigranten-kolonie denkt: „de immigranten moeten door „directen of indirecten 
„dwang" zoowel in hun eigen belang als in dat der geheele „kolonie tot een behoorlijke arbeidsprestatie worden opge„voed"; en is een ,krachtige en strenge leiding der Gou„vernements-vestigingsplaatsen noodig".

Blijkbaar zit dus de gedachte voor aan eene ,gemeenschap" en wel eene in wezen overeenkomende met de Javaansche desa, wier bewoners ook door ,zachten dwang” (printah aloes) door het desa-hoofd en zijne trawanten naar de sawahs worden geleid tot het op gezette tijden bewerken der velden, planten en oogsten van de rijst, daar anders weldra hongersnood voor de deur zou staan. En zoo zou dan in Suriname de Javaansche desa haar intrede doen, met dit verschil echter dat het Gouvernement de installatie-kosten draagt niet alleen, doch ook voor het onderhoud der kolonisten zal moeten zorgen, indien de werkgelegenheid niet voldoende daarvoor aanwezig is. De leiding der Gouvts Vestigingsplaats moge dan nog zoo ,krachtig en streng” zijn, zij zal nimmer in staat zijn de psyché der Javaansche immigranten te veranderen, en het is niet duidelijk wat overigens van dat strenge optreden verwacht kan worden tegenover de gelatenheid en het fatalisme van den Javaan. Er behoort m.i. wel een bijzonder groot optimisme toe om van hem méér arbeid te verwachten dan hij voor zijn levensonderhoud en dat van zijn gezin strikt noodig heeft; een dergelijk stelsel kan m.i. nimmer tot „krachtige kolonisatie en een sterke toeneming van den stand der kleine landbouwers" leiden; integendeel is het niet moeilijk te voorspellen dat het niet anders dan tot groote teleurstelling en vergeefsche kosten zal leiden, het tijdverlies nog buiten beschouwing gelaten.

Ook om het bovenaangehaalde verdient het aanbeveling de immigratie slechts naar de behoefte te doen plaats hebben.

De vraag rijst: Waarom moet hier uitsluitend aan zelfstandige Javaansche kolonisten gedacht worden, waar deze noch door hunne kunde noch door hun aanleg daartoe geschikt zijn? Hier is plaats voor iets anders en beters: Europeesche kolonisten als klein-ondernemers, werkende met Javaansche arbeiders voor het zware veldwerk. 


\section{Kolonisatie}

Werden hiervoren de bezwaren van psychischen, agrarischen en finantieelen aard naar voren gebracht, welke aan de verwezenlijking van het denkbeeld: „Zelfstandige Javaansche kolonisatie" in den weg staan, thans moge het stelsel aangewezen worden, dat ik daarvoor in de plaats zou willen aanbevelen: „Europeesche kolonisten als klein-ondernemers, werkende met Javaansche arbeiders (eventueel negers), deze klein-ondernemers al dan niet als aanhangsel van - resp.: leveranciers van de grondstoffen aan de groote landbouw-bedrijven, al naar gelang van den aard der door hen geteelde producten en afhankelijk van de streek van vestiging.

Deze wijze van kolonisatie (waarvan de plaats in het stelsel en de verhouding tot de grootbedrijven nader zal worden omschreven) heeft verschillende voordeelen, waarvan wij in de eerste plaats zouden willen noemen de mogelijkheid voor het klein-kapitaal tot belegging in Suriname en door het stichten van kleinere hoeven (50-100 H.A.) eene gezonde ontwikkeling van het individueel initiatief te bevorderen door de gelegenheid te openen voor jonge landbouwers met eenig kapitaal om door ijver, kunde en organisatie-vermogen tot welvaart te komen, waartoe in Nederland de gelegenheid steeds moeilijker wordt.

Ook zou in dit verband plaats zijn voor jongelieden met landbouwkundige opleiding die na eenige jaren practijk een zelfstandigen werkkring verkiezen boven het werken in loondienst van een grooten ondernemer of maatschappij, waar de genoemde prikkel ontbreekt, althans niet in die mate aanwezig is en de kans om aan het hoofd der onderneming te komen in ieder geval geringer is; bovendien zijn niet alle daartoe geschikt of aangewezen, terwijl zij als klein-ondernemer zeer goed op hun plaats kunnen zijn.

Deze hoeven stel ik mij voor als landbouw-, veeteelt- of gemengd bedrijf, waarop dus zoowel vee gehouden kan worden voor het verkrijgen van zuivelproducten als voor 
levering van slachtvee aan bevroren-vleesch inrichtingen voor den uitvoer; en landbouw-producten geteeld kunnen worden voor eigen gebruik en export, zooals die in alle Zuid-Amerikaansche republieken bestaan en b.v. in Brazilië onder den naam "fazenda's" onder analoge omstandigheden als in Suriname heerschen een onmisbare schakel vormen in het economische bedrijfsleven, geknipt als zij zijn voor en trouwens hun ontstaan danken aan den economischen toestand in schaars bevolkte landen (nog geaccentueerd na de afschaffing der slavernij), de daar gevolgde werkwijzen en de productievormen ${ }^{1}$ ).

\section{Uitvoer: doel der bedrijven}

Als doel der bedrijven staat voorop het leveren van producten voor uitvoer. Vermeldden wij reeds wat de veeteelt betreft het fokken van vee voor levering aan bevrorenvleeschinrichtingen, zoowel als het verkrijgen van zuivelproducten (boter en kaas) voor export, hieraan is nog toe te voegen de hooihandel in geperste balen, welke b.v. in Argentinië een aparte tak van bedrijf is geworden en groote afmetingen heeft aangenomen; van landbouwproducten noemen wij rijst en mais om opgekocht te worden door de overzeekantoren der groote exporthuizen met hoofdzetel in Europa, zooals dit in Argentinië eveneens met mais, graan, lijnzaad enz. plaats heeft. Hier ligt voor de bij dien handel betrokken huizen nog een onmetelijk onontgonnen terrein open.

Voor een jong land dat tot ontwikkeling moet worden gebracht is de normale ontwikkelingsgang die via de kleinbedrijven, welke later tot groot-bedrijven kunnen uitgroeien, hetzij door vereeniging van eenige daarvan of wel door uitbreiding.

Op deze wijze zal eene particuliere kolonisatie ontstaan waarbij de betrokkenen, in tegenstelling van hetgeen bij Rijks-kolonisatie plaats heeft, van den aanvang af $o p$ eigen krachten zullen hebben te bouwen, hetgeen de beste

$\left.{ }^{1}\right)$ Statistieken der door de kolonisten in de Staten Minas Geraes en Rio de Janeiro geproduceerde producten voor export zijn ter beschikking van belangstellenden. Deze koloniën bestaan grootendeels uit Duitschers, Zweden en Noren. 
waarborg is voor het slagen. Overheidssteun doodt het initiatief en de vindingrijkheid, welke juist de hoofdeigenschappen van den kolonist moeten zijn.

De door den Staat bij de Kolonisatie door particulieren te bieden hulp zal m.i. moeten bestaan in: het op gemakkelijke voorwaarden verkrijgbaar stellen van gronden; het verleenen van transport-gelegenheid; onderstand der kolonisten voor beperkten duur; assaineering.

Wat dit laatste betreft wordt ons door Brazilië een werkelijk schitterend voorbeeld gegeven, waar Dr. Oswaldo Cruz er in weinige jaren in geslaagd is de beruchte gele koorts en pest geheel te doen verdwijnen en malaria tot zeer enge grenzen heeft teruggebracht. (Zie J.C. Oakenfull. „Brazil”. Uitg.: Butler \& Tanner, Selwood PressFrome (Engeland).

Is aan de economische eischen van voortbrenging voldaan, dan zal het grootkapitaal, dat steeds dáár gaat, waar het voordeel ziet, ook in Suriname belegging zoeken. Zonder behoorlijken ondergrond als hiervoren uiteengezet, is dit nauwlijks te verwachten; m.i. is het in dat kapitaal hoogelijk te apprecieeren dat het geene millioenen beschikbaar stelt voor ondernemingen, indien niet de levensvatbaarheid daarvan practisch is a angetoond. Immers, bij het niet uitblijvende echec door onvoldoende voorbereiding zou dit de goede zaak een slechten dienst bewijzen; proefnemingen daargelaten.

Waar de genoemde producten reeds in Suriname verbouwd worden, zij het op kleine schaal door de kolonisten, kan eene eventueel uit te zenden Commissie als Vertegenwoordigende eene groep belangstellenden in de Kolonisatie zich van de omstandigheden ter plaatse overtuigen en daarvan rapport uitbrengen aan hunne Vertegenwoordigden, zooals zulks reeds meermalen geschied is naar Zuid-Afrika, met het gevolg dat een groep landbouwers daarop haar besluit baseert tot emigratie, zooals nu onlangs weder een 20 tal vertrokken is naar de KendrewEstate bij Graaf Reynet om de vruchtencultuur uit te oefenen op irrigeerbare velden. 
Wanneer dus contact gezocht wordt met landbouwvereenigingen kan deze zaak daar aanhangig gemaakt worden $\left.{ }^{1}\right)$.

Deze beschouwingen zouden niet volledig zijn, zonder de al of niet geschiktheid van den Noord-Europeaan voor kolonisatie in Suriname te vermelden. Betreffende deze questie loopen de meeningen zeer uiteen, vastgekoppeld als zij dikwerf wordt aan de al of niet wenschelijkheid van gekleurde werkkrachten voor de grootbedrijven.

Het is hier niet de plaats noch acht ik mij bevoegd een definitief oordeel uit te spreken over de vraag of Suriname voor Europeesche kolonisatie geschikt is, al zou ook mijne persoonlijke ervaring in streken onder analoge omstandigheden en even hooge temperatuur mij deze vraag bevestigend doen beantwoorden. Bij objectieve beschouwing en raadpleging van bestaande lectuur, statistieken enz. van aangrenzende landen blijkt de tropische temperatuur alléén geen beletsel daartoe te zijn, mits op sanitair gebied de noodige voorzieningen worden getroffen. (Men leze hierover: „Four Brazilian States” van Julio Pompeu - Uitg. Typogr. Leuzinger-Rio de Janeiro).

Zooveel is in ieder geval wel zeker dat de billijkheid eischt onzen Nederlandschen landbouwers minstens evengoed een ,fair chance” te geven als den Javanen en valt het moeilijk aan te nemen dat er eene Nederlandsche Regeering te vinden zou zijn die onze landbouwers zou achterstellen bij ongeschoolde Javaansche arbeiders, die in de buitenbezittingen nog een ruim expansie-gebied bezitten.

Hebben in het voorafgaande de persoonlijke factor en de te verbouwen producten een punt van beschouwing uitgemaakt, ten slotte mogen eenige terreinen worden genoemd welke voor kolonisatie in aanmerking komen:

$1^{\circ}$. De alluviale laagland-terreinen.

Aan de hand van het artikel van den Heer Tj. Pyttersen (W. I. Gids Dec. '22) komt de streek, ingesloten

\footnotetext{
1) Overigens zij voor inlichtingen betr. klimaat onz. verwezen naar het art. van den Hr. T. Pyttersen "Opbouw" in den W. I. Gids van Dec. '22 en Mei, Juni en Nov. 23.
} 
door de Nickerie-Rivier, de Wajombo en de Coppename, ongeveer $400.000 \mathrm{H}$. A. groot, volgens de gegevens bij de Waterpassing verkregen, in aanmerking voor rijst- en suikerriet cultuur waarop dus voor een groot aantal suikerfabrieken ruimte is, met in achtneming van behoorlijken wisselbouw met rijst. Vooraf zal dit terrein echter gedraineerd moeten worden en voor een afscheepgelegenheid der producten, tevens aanvoerplaats voor machineriën enz. gezorgd dienen te worden. De kosten hiervan behoeven niet enorm hoog te zijn. Bij baggering van een afvoerkanaal met een profiel van $10 \times 2 \mathrm{M}^{2}$. en voorloopig $10 \mathrm{~K} . \mathrm{M}$. lengte $=200.000 \mathrm{M}^{3}$. grondverzet à $f 0.40$ p. $\mathrm{M}^{3}{ } .=f l .80 .000$, waarbij dan komen sluiswerken, gezamenlijk hoog getaxeerd à $f 2$ ton .

Een eenvoudige aanlegsteiger op schroefpalen met plankbedekking, 100 Meter lang en $15 \mathrm{M}$. breed met een drietal loskranen is ongeveer op hetzelfde bedrag te schatten.

Wanneer men bedenkt dat die vlakte ongeveer voor 40 suikerfabrieken van groote capaciteit plaats biedt, verzinken deze kosten in het niet tegenover de inkomsten, door den staat daarvan te trekken. Om de hiervoren genoemde Kendrew-Estates van bevloeiingswater te voorzien besteedde de Unie-Regeering in Zuid-Afrika $£ 400.00$ dus juist $12 \times$ zooveel voor eene $10 \times$ kleinere oppervlakte; when a thing is worth doing, it is worth doing well!

II. Het terrein tusschen de genoemde alluviale laagvlakte en de eigenlijke Savannen hetwelk reeds vroeger door de suikercultuur in gebruik was genomen en ook voor veeteelt en mais zéér geschikt is bevonden. Deze streek komt dus voor de Vrije kolonisatie in aanmerking, zooals boven omschreven.

III. De eigenlijke Savannen. Zooals bekend zijn deze terreinen (en ook sommige der onder II genoemde) een gedeelte van het jaar overstroomd door de ondoorlatendheid van den bodem wegens een zich op \pm 1 Meter en meer daaronder bevindenden oerbank, in andere tijden zóó droog, dat zij slechts voor weinige planten geschikt zijn. Het zou te ver voeren aan te toonen, dat dezegronden, 
wat samenstelling betreft, tot de vruchtbaarste gerekend moeten worden; kortheidshalve zij verwezen naar de brochure van Essed B. Sc. Edinb overgedrukt uit de „Periskoop" van Febr. 1926.

Wat het middel betreft dat in deze brochure aangeprezen wordt om het genoemde euvel te verhelpen en deze gronden geschikt voor den landbouw te maken n.l. het graven van een groot aantal evenwijdige en loodrecht daarop staande afvoerkanalen, meen ik dit stellig te moeten ontraden vooreerst om de hooge kosten en tweedens wijl door drainage de gronden nog droger zouden worden.

Er bestaat daarvoor een ander middel n.l. het beplanten met alfalfa, een klaversoort met een zéér uitgebreid en diepgaand wortelstelsel, dat tot 5 Meter diep gaat en de voor water ondoordringbare laag doorboort, waardoor eene natuurlijke draineering bereikt wordt met benutting van het regenwater. Daar deze alfalfa tot de vlinderbloemigen behoort, zal zij bovendien nog tot verbetering van de gronden bijdragen. Deze alfalfa levert eenige snitten per jaar en zelfs de dorste zandvlakten zijn daardoor in vruchtbare streken herschapen. (provincie Mendoza in Argentinië).

Wat veeteelt voor deze streken betreft, verwijzen wij naar het artikel van den Hr. J. W. Gonggrijp in den W. I.-Gids Nov. 1923.

IV. De hooger (tot 1200 M. hoogte) gelegen, thans nog met oerbosch bedekte terreinen. Deze, zich tot de Braziliaansche grens uitstrekkende terreinen, leenen zich zoowel door ligging als samenstelling voor hooglandcultures; en speciaal voor Europeesche Kolonisatie door het frisschere bergklimaat.

Ik ben gaarne bereid wat Kolonisatie betreft belangstellenden in te lichten omtrent de in Brazilië en Argentinië bereikte resultaten door Noord-Europeesche kolonisten.

Dordrecht, Juni 1927. 